\title{
MUHASEBE BİLİRKİŞİLİĞİ KAPSAMINDA İŞÇİ ALACAKLARI ÜZERİNE BİR UYGULAMA
}

Murat ÖZDEMIR 1

$\ddot{O Z Z}$

\section{AnahtarKelimeler: \\ Muhasebe \\ Adli Muhasebe \\ Muhasebe Bilirkişiliği \\ İşçi Alacakları}

JEL Kodlan:

\author{
Received Date (BaşvuruTarihi): \\ Accepted Date (Kabul Tarihi): \\ Published Date (YayınTarihi):
}

$1 / 04 / 2020$

$30 / 05 / 2020$

$25 / 06 / 2020$

\begin{abstract}
M40
M41

Keywords:

Accounting Forensic Accounting Accounting Expert Witness Receivables of Employee

JEL Codes:

M40 gösterdiği ve iş̧̧ alacaklarmın hesaplanmasında diğer dava türlerine nazaran daha komplike bir durum söz konusu olduğu tespit edilmiştir.

JEL Codes: $\quad$ M40 $\quad$ M41
\end{abstract}

Muhasebe bilirkişiliği, mahkemelere mali konularda destek hizmetleri sağlayan ve uyuşmazlıklarm çözümünde önemli rol oynayan mesleki faaliyetlerden biridir. Günümüzde görülen çeşitli davalarda muhasebe bilirkişilerine ihtiyaç duyulmaktadır. Bu bağlamda çalışmada önce bilirkişilik ve muhasebe bilirkişiliği üzerinde teorik olarak durulmuş, sonrasında işçi alacaklar hesaplamalarm içeren bir uygulamaya yer verilmiştir. Çalışmanın amacı, iş̧̧i alacaklarının hesaplanmasında göz önünde bulundurulacak hususlarn belirlenmesi ve bu konuda hazırlanacak bilirkişi raporlarına yön verebilecek genel bir çerçevenin oluşturulmasıdır. Çalışmanın sonucuna göre iş mahkemelerinde hesap bilirkişiliği kapsamında yapılan hesaplamalarda maddi hukuk kadar alışılagelmiş uygulamalarn da önemli olduğu belirlenmiştir. Ayrica bilirkişi tarafindan göz önünde bulundurulan etkenlere bağll olarak hesap tutarlarmın oldukça farklilık

${ }^{1}$ Dr. Öğr. Üyesi, Giresun Üniversitesi, murat.ozdemir@giresun.edu.tr,

https://orcid.org/0000-0001-6608-6511

Business \& Management Studies: An International JournalVol.:8 Issue:2 Year:2020,1823-1848

Bu makale, araştırma ve yayın etiğine uygun hazırlanmış ve 


\section{EXTENDED ABSTRACT}

\section{AN APPLICATION ON RECEIVABLES OF EMPLOYEE WITHIN THE SCOPE OF ACCOUNTING EXPERT WITNESS}

\section{INTRODUCTION}

Accounting expertise is one of the professional activities that provides courts with support services on financial matters and plays an important role in the resolution of disputes. Accounting experts are needed in today's various cases. In this context, Brennan (2005) examined the expertise roles of accounting professionals in the resolution of disputes in England and North America perspective. He stated that this expertise duty had different standards than other accounting duties. He referred to the quality and importance of the expert evidence. Sanchez and Zhang (2012) stated in their studies that they examine the qualifications of experts, that experts are used in many cases and play a very important role in resolving cases. In this context, they have demonstrated the importance of experts in resolving two high profile fraud cases known as Enron and Healthsouth.

\subsection{Purpose, Importance and Method of the Study}

In recent years, although there is a need for accounting expertise in various dispute issues, disputes between workers and employers are more clearly felt in labor courts. Although there are certain standards in the reports prepared by the accounting experts, the calculations made by different experts show different results and the numbers do not match, depending on the factors considered. In this context, the aim of the study is to determine the indicators to be taken into account in the calculations to be made within the scope of the accounting expertise, to determine the paths to be followed in order to create the expert report and to form a framework for these calculations. Accordingly, in the first part of the study; the expertise, accounting expertise and expertise issues in the labor courts have been briefly examined theoretically, and in the second part, the application for calculating the receivables claimed in a case between the employee and the employer is included.

There are theoretical studies on accounting expertise in the literature, but there are not many studies on practice. This aspect emphasizes the importance of the study.

The study was carried out by the method of evaluating and calculating each receivable item separately in line with the relevant legislation and laws, labor contracts, documents available in the file, information and other documents obtained as a result of on-site inspections.

\subsection{Account Expertise in Labor Courts}

Expertise in the field of accounting is the presentation of special or technical information required to the court in all kinds of financial cases related to accounting (K1sacik, 2018: 300). This special and technical information may be related to laws such as; The Turkish Commercial Code (TCC), Tax Procedure Law (TPL) and special tax laws, the Code of Obligations, the Capital Market 
Law (CML) and the Labor Law. Because these laws also contain regulations on accounting practices (Akyel, 2016: 97). It is quite natural that the examinations to be carried out in terms of the basic concepts of accounting and the principles of financial statement editing are carried out by experts of the subject (Utku and Kurtcebe, 2019: 266). The appointment of professional accountants as experts arises from the need for knowledge, experience and competence in this regard.

The increasing number of business disputes has increased the need for an accounting expert in this area. As mentioned before, a significant part of the disputes in the labor courts belong to workers' receivables. The calculation of workers' receivables takes place on the basis of the Supreme Court's jurisprudence and the principles of proof law, as well as material law information (www.bilgi.edu.tr). In other words, it is not enough to know the material law in accounting expertise, besides, the procedural provisions in the Civil Procedure Law (HMK) should be known and these rules should be observed in line with the decisions of the Supreme Court. Because procedural rules can sometimes prevent material law. In this sense, the following issues will be effective in taking into account the report to be prepared in expert judgment practices in labor courts (Bozkurt, 2009: 118).

- Limited to Demand

- Consideration of the Timeout Define

- Consideration of Documents

- Appreciation Discount (Fairness Discount)

Some examinations and determinations requested by the courts in the cases of worker receivables can be listed as follows.

- Examination of documents such as seizure charts, payroll records, payment documents regarding social benefits, all documents related to additional payments, account statements,

- Determining how payments are made,

- The subject of the case is to determine whether the receivables exist.

In the examination of the records and documents subject to expert calculations; issues such as arithmetic accuracy, whether there are authorized signatures, whether they track consecutive sequence numbers and dates, whether they are filed correctly or not, are investigated. This research and investigation can be done in two ways (Selimoğlu et al., 2014: 146).

a) Forward examination of records

b) Backward examination of records 
If the receivables subject to the case cover a long period, it is more rational in terms of revealing the results from the known to the unknown, that is, the backward examination of the records.

The labor law, collective labor agreements and service contracts that are in force in the labor judiciary should be taken into consideration primarily. In reviews and calculations; documents such as payrolls, annual leave books, personal file, SSI registration file, payment receipts, release documents, witness statements, minutes and payroll lists are very important.

\section{CONCLUSION}

The business relationship between the worker and the employer is among the fields of activity of the accounting profession. With the signing of the employment contract, the process until the submission of the declaration of employment, making payments such as wages and attachments to be paid, and even signing the employee upon termination of the employment contract takes place under the control of the accounting members. Therefore, courts frequently apply to accounting experts in workers' receivables cases and provide the special and technical information needed in this field from the professionals.

In Turkey, many arrangements have been made with the Expertise Law No. 6754 for the elimination of the problems observed in the expertise practices and the establishment of an effective structure. These regulations institutionalized the expertise institution and increased the qualifications of the experts with certain standards. However, some problems still persist from past to present. The files are still handed over and delivered to the experts appointed by the courts, and it takes quite a while to get to and from the court items. In fact, this problem can be solved by using the UYAP Expert System effectively. However, for this, the staff working in the court items must fully adapt to the system. Another problem is that the expert fees do not meet the labor provided. This causes most of the professions to stay away from the expertise issue.

As a result, in the study on accounting expertise, the questions asked by the court to answer the expert in an exemplary case regarding workers' receivables were emphasized and the study was completed by not paying much attention to legal facts. In the similar studies to be carried out in the future, other types of cases involving financial issues can be examined through case studies and the literature can be contributed within the scope of accounting expertise. 


\section{GİRIŞ}

Muhasebe alanında yaşanan gelişmeler mesleki faaliyetlerin çeşitliliğine neden olmakta, muhasebe mensuplarının sorumluluklarını günden güne arttırmaktadır. İşletme, devlet, finans kuruluşları, çalışanlar gibi kısaca muhasebe bilgi kullanıcılarına düzenli, güvenli ve doğru bilgiler sunan muhasebe, mahkemelere de mali konular hakkında ihtiyaç duyulan hizmetleri muhasebe bilirkişiliği yoluyla sunmaktadır. Muhasebe bilirkişileri, mali konuları içeren davalarda hâkimin olaylar ve olgular hakkında değerlendirme yapabilmesine ve bu değerlendirmeler sonucunda bir karara varabilmesine yardımcı olan özel veya teknik bilgileri sağlayan yetkin ve tecrübeli meslek mensuplarıdır.

Son yıllarda çeşitli uyuşmazlık konularında muhasebe bilirkişiliğine ihtiyaç duyulmakla birlikte iş mahkemelerinde işçi ve işveren arasındaki uyuşmazlıklarda daha belirgin bir şekilde hissedilmektedir. Muhasebe bilirkişiliği kapsamında hazırlanan bilirkişi raporlarında belli bir standart bulunmamakta, hazırlayan meslek mensubunun bakış açısına göre değişebilmektedir. Bu bağlamda çalışmada, iş mahkemelerinde sıklıkla uyuşmazlığa konu olan fazla çalışma ve ilave tediye gibi bazı alacakların hesaplaması konusu üzerinde durulmuştur.

Çalışmanın amacı, muhasebe bilirkişiliği kapsamında yapılacak hesaplamalarda göz önünde bulundurulacak göstergelerin belirlenmesi, bilirkişi raporunun oluşturulabilmesi için izlenecek yolların tespit edilmesi ve söz konusu hesaplamalara bir çerçeve oluşturulmasıdır. $\mathrm{Bu}$ doğrultuda çalışmanın ilk bölümünde; bilirkişilik, muhasebe bilirkişiliği ve iş mahkemelerinde bilirkişilik konuları teorik olarak kısaca incelenmiş, ikinci bölümde ise işçi ve işveren arasında görülen bir davada iddia edilen alacakların hesaplanmasına yönelik uygulamaya yer verilmiştir.

\section{BİLIRKISŞİLIK KAVRAMI}

Geçmişten günümüze sıklıkla başvurulan bilirkişilik müessesesi, genel olarak yargılama hukukuna ait ve bu alan ile özdeşleşen bir müessesedir (Soydan ve Biyan, 2016: 133). Bilirkişilik müessesesi, hukuki bilgilerle çözülemeyecek ölçüde teknik ve mesleki bilgi içeren uyuşmazlıkların çözümünde, mahkemelerin alanında uzman 
kişilerin incelemelerine dayanarak karar vermelerini sağlayan müessesedir (Utku ve Kurtcebe, 2019: 263).

Türkiye'de bilirkişilik hizmetlerinin düzenli, etkin ve verimli olarak yürütülmesi amacıyla 24.11.2016 tarih ve 29898 sayılı Resmî Gazete'de yayımlanan 6754 sayılı Bilirkişilik Kanunu yürürlüğe girmiştir. Bilirkişilik müessesesini modern bir yapıya kavuşturan bu kanun ile bilirkişiliğin tüm boyutları ele alınmış, bilirkişilerin kalite standartlarının tesisi ve etkin bir denetim mekanizması oluşturulması hedeflenmiştir. Yine kanunla birlikte Adalet Bakanlığı Hukuk İşleri Genel Müdürlüğü bünyesinde "Bilirkişilik Daire Başkanlığı” kurulmuş (ASMMO, 2017; www.bilirkisilik.adalet.gov.tr) ve 03.08.2017 tarihinde Bilirkişilik Yönetmeliği yayımlanmıştır. Bilirkişilik Kanunu ve yönetmeliği çerçevesinde bilirkişiler için 24 saatlik zorunlu olan "Bilirkişilik Temel Eğitimi” getirilmiştir. Bu eğitim bilirkişilik görevi sırasında ihtiyaç duyulan temel bilgileri içermektedir (Utku ve Kurtcebe, 2019: 263).

Türk Dil Kurumu'na (TDK) göre, bilirkişi belli bir konudan iyi anlayan ve bir anlaşmazlığı çözümlemek için kendisine başvurulan kimse, ya da çözümlenmesi özel veya bilimsel bilgiye dayanan konularda reyine veya fikrine başvurulan kimse, uzman, ehlivukuf olarak tanımlanmaktadır. Literatürde başkaca tanımlar da bulunmaktadır. Örneğin; bir uyuşmazlığın temelini oluşturan olgu ve olayları saptayan, aydınlanması ve değerlendirilmesi için teknik tespitler yapan ve bu göreviyle hâkime yardımcı olan kişiye bilirkişi denir (Köroğlu, 2001: 31). Bir başka ifade ile bilirkişi “Çözümü uzmanlığı, özel veya teknik bilgiyi gerektiren hallerde oy ve görüşünü sözlü veya yazılı olarak vermesi için başvurulan gerçek veya özel hukuk tüzel kişisidir" (Erdoğan, 2017: 48).

Mahkemeler çözümü özel veya teknik bilgi gerektiren durumlarda taraflardan birinin talebi üzerine veya kendiliğinden bilirkişinin oy ve görüşünün alınmasına karar verebilir. Bununla birlikte genel bilgi ya da tecrübeyle veya hâkimlik mesleğinin gerektirdiği hukuki bilgilerle çözümlenebilecek konularda bilirkişiye başvurulmaz (HMK, md.266). Zira mahkemenin hukuki bir konuda bilirkişi incelemesine başvurması, yargılama yetkisinin devri anlamina gelmekte ve Anayasa'ya aykırılık teşkil etmektedir (Toraman, 2017: 98). 
Bir davada bilirkişiye başvurulup başvurulamayacağı ya da diğer söylemle özel veya teknik meselenin mevcut olup olmadığı hâkimin takdir yetkisindedir. Şayet hâkim bilirkişiye başvurmaya karar vermişse, özel veya teknik meselenin niteliğini, kapsamını ve konuyla ilgili görevlendireceği bilirkişiyi de belirleyecektir (Organ ve Sevinç, 2016: 118). Ayrıca mahkeme, bilirkişi olarak sadece bir kişiyi görevlendirebileceği gibi gerekçesinin açıkça gösterilmesi suretiyle, tek sayıda birden fazla kişiden oluşan bir kurulu da görevlendirebilecektir (HMK, m267).

Hâkimin bir dava ile ilgili özel ve teknik bilgi ihtiyacı üç şekilde ortaya çıkabilmektedir (Erdoğan, 2017: 48);

- Salt olarak özel ve teknik bilginin mahkemeye iletilmesi,

- Özel ve teknik bilginin vakıalara uygulanmasıyla varılan sonucun iletilmesi,

- Özel ve teknik bilgi vasıtasıyla salt bir vakıanın tespit edilmesi.

Bilirkişiler, hâkimin yardımcısı konumundadır. Ancak hemen belirtmek gerekir ki hâkim, bilirkişinin oy ve görüşüne bağlı olmayıp diğer deliller gibi serbestçe değerlendirir (HMK, m. 282). Bilirkişilerin oy ve görüşü, usul hukuku bakımından ve niteliği itibariyle takdiri deliller arasında sayılmaktadır. Deliller, bir davanın dayanağı olan maddi vakıaların ispatını sağlayan araçlardır (Aksu, Uğur ve Çukacı, 2008: 68).

\subsection{Muhasebe Bilirkişiliği}

Mahkemeler çeşitli uyuşmazlıklarda muhasebe alanında da bilirkişilere başvurmaktadır. Bilindiği üzere muhasebe; mali olayları, muhasebe ilke ve standartları içerisinde kaydedip, sınıflandıran, özetletip analiz eden ve ilgili muhasebe bilgi kullanıcılarına raporlayan bir uzmanlık alanıdır. Bu uzmanlık alanında faaliyet gösteren meslek mensuplarını ise Serbest Muhasebeci Mali Müşavirler (SMMM) ve Yeminli Mali Müşavirler (YMM) oluşturmaktadır.

Muhasebe alanında bilirkişilik, muhasebeyle ilgili her türlü mali nitelikteki davalarda gereken özel veya teknik bilgilerin mahkemeye sunulmasıdır (Kısacık, 2018: 300). Bu özel ve teknik bilgiler; Türk Ticaret Kanunu (TTK), Vergi Usul Kanunu 
(VUK) ve özel vergi kanunları, Borçlar Kanunu (BK), Sermaye Piyasası Kanunu (SPK) ve İş Kanunu gibi kanunlarla ilgili olabilmektedir. Çünkü söz konusu kanunlar aynı zamanda muhasebe uygulamalarıyla ilgili düzenlemeleri de içermektedir (Akyel, 2016: 97). Dava dosyalarında muhasebenin temel kavramları ve finansal tablo düzenleme ilkeleri açısından yapılacak incelemelerin konunun uzmanları tarafından yapılması son derece doğaldır (Utku ve Kurtcebe, 2019: 266). Muhasebe meslek mensuplarının bilirkişi olarak görevlendirilmesi bu konudaki bilgi deneyim ve yetkinlik ihtiyacından ortaya çıkmaktadır.

Muhasebe bilirkişisi mahkeme tarafından görevlendirildiğinde yaşanan süreç, aşamalar halinde Şekil 1'de sunulmuştur.

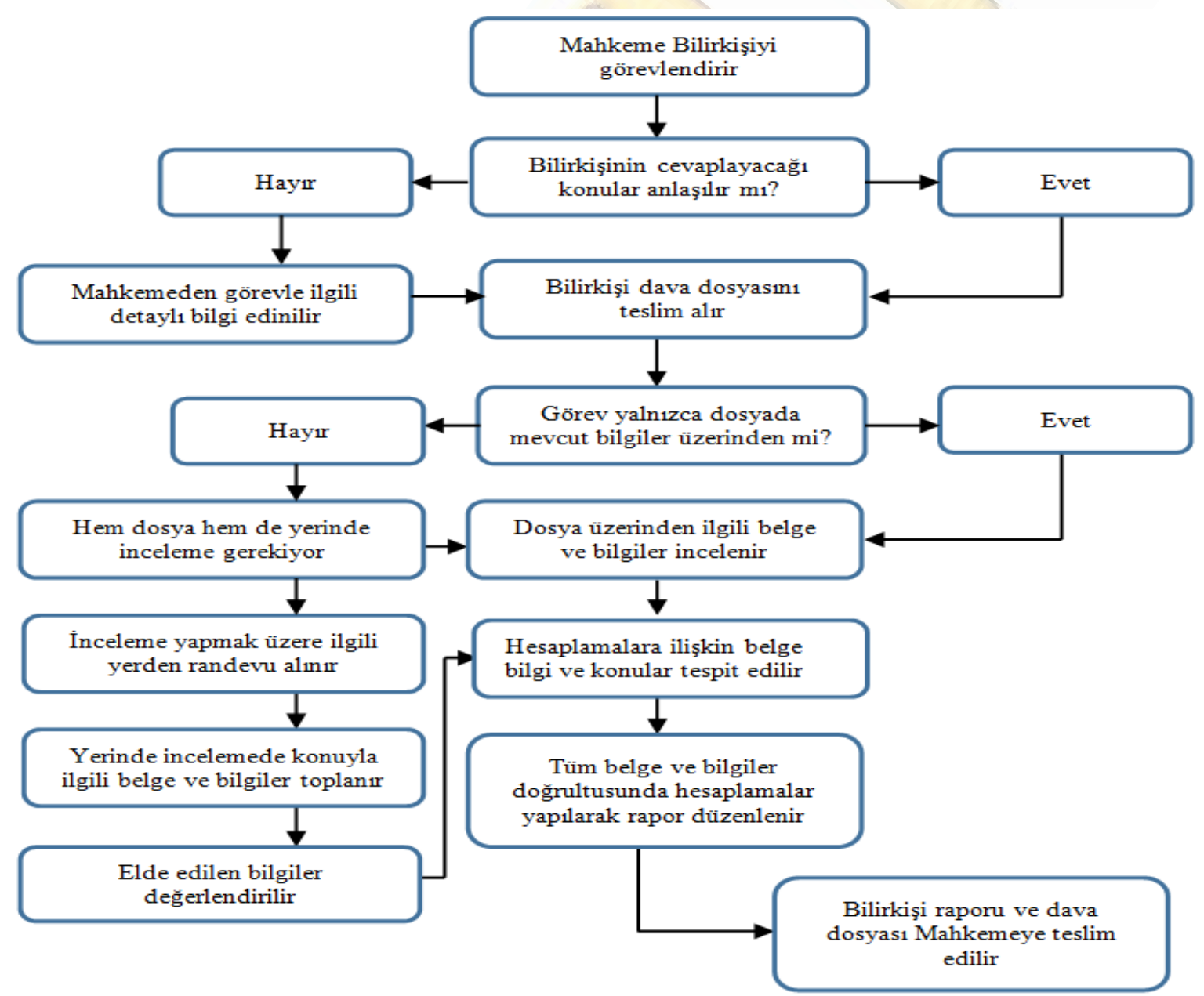

Şekil 1. Muhasebe Bilirkişiliği Süreci

Şekil 1'den de anlaşılacağı üzere bilirkişi görevlendirilmesi sadece dosyada mevcut belge ve bilgiler üzerinden ya da hem dosya hem de yerinde yapilan inceleme ve tespitlerden oluşmaktadır. 


\section{2. İş Mahkemelerinde Bilirkişilik}

İşçi ve işveren arasında yaşanan uyuşmazlıklar sonucu açılan davalar, iş mahkemelerinde görülmektedir. Türkiye'de İş mahkemeleri, 5521 sayılı "İş Mahkemeleri Kanunu" ile kurulmuştur. İş mahkemesi, tek hâkimli ve özel mahkemedir. Sanayileşmenin ve iş uyuşmazlıklarının yüksek oranda olmadı̆̆ı yerlerde iş mahkemesi kurulmamıştır. İş mahkemesi kurulmayan bu yerlerde iş uyuşmazlıkları, iş mahkemesi sıfatıyla Asliye Hukuk Mahkemelerinde görülmekte ve karara bağlanmaktadır (Mülayim, 2018).

İş Mahkemelerinin bilirkişi incelemelerine en çok başvuran mahkemelerden olduğu bilinmektedir. İş mahkemeleri, uyuşmazlıklarda ortaya çıkan alacak davaları, iptal davaları, tespit davaları ve itiraz davaları gibi davalarda bilirkişi incelemesine gerek duymaktadır. Yüzlerce çeşit davayı içeren bu disiplinde daha çok kusur bilirkişiliği ve hesap bilirkişiliği ön plan çıkmaktadır. Kusur bilirkişiliği ihtiyacı, iş kazaları ve rücu davalarında kazadaki kusur dağılımı, işverene zarar veren işçinin kusur derecesi, kusur durumun araştırılması gereken alacak davaları gibi davalarda, hesap bilirkişiliği ihtiyacı ise kıdem-ihbar tazminatı, ücret ve ekleri alacakları, istirdat davalar1 ${ }^{2}$, olumlu tespit davalar1 ${ }^{3}$, olumsuz tespit davalar1 ${ }^{4}$, iptal davalar1 ${ }^{5}$ ve itiraz davaları ${ }^{6}$ gibi davalarda ortaya çıkmaktadır (Bozkurt, 2009: 117).

Günümüzde iş uyuşmazlıklarının artması, bu alanda giderek artan bir şekilde hesap bilirkişisi ihtiyacını ortaya çıkarmıştır. Daha önce de ifade edildiği gibi iş mahkemelerinde görülen uyuşmazlıkların önemli bir kısmı işçi alacaklarına aittir. İşçi alacaklarının hesaplanması maddi hukuk bilgisinin yanında Yargıtay içtihatları ve ispat hukuku esasları ile olmaktadır (www.bilgi.edu.tr). Başka bir söylemle hesap bilirkişiliğinde sadece maddi hukukun bilinmesi yeterli olmayıp bunun yanında Hukuk Muhakemeleri Kanunu'ndaki (HMK) usul hükümlerinin bilinmesi ve bu kuralların Yargıtay kararları doğrultusunda gözetilmesi gerekir. Çünkü usul kuralları kimi zaman maddi hukukun önüne geçebilmektedir (Bozkurt, 2009: 118).

\footnotetext{
2 Fazla ödenen kıdem tazminatının geri alınması vd.

${ }^{3}$ Belirli tarihlerde çalıştığının tespitini talep eden hizmet tespiti davaları

${ }^{4}$ Prim borcunun bulunmadı̆̆ının tespiti

${ }^{5}$ Yaşlılık aylığının hak kazandığının tespiti vd.

${ }^{6}$ Ödeme emine itiraz gibi.
} 


\subsubsection{Taleple Sinırlı Kalınması}

İş mahkemesinde görülen bir alacak davasında talepten fazlasına karar verilemeyeceği, iddia veya savunmada yer verilmeyen hususların hatırlatılmasına yol açacak bir işlem yapılamayacağı gibi düzenlemeler bulunmaktadır (HMK, m. 2526). Hâkim için yapılan bu düzenlemeler aynı zamanda bilirkişiler için de geçerlidir. $\mathrm{Bu}$ bağlamda hesap bilirkişileri aşağıdaki hususlara dikkat etmesi gerekir (Bozkurt, 2009: 118)

- Bilirkişi, savunma veya iddiayı aşarak ibraz edilmeyen belgelerin ibrazını isteyemez.

- Bilirkişi, talep edilmeyen bir alacağın hesaplamasını yaparak, raporunda gösteremez.

- Bilirkişi, taraflar arasında tartışmalı olmayan bir konuda ihtilaf çıkaramaz; tartışmasız konuları ayıklar, yalnızca tartışmalı konuları değerlendirir.

\subsubsection{Zamanaşımı Definin Dikkate Alınması}

Defi, davalının esasında borçlu bulunmasına rağmen, borçlu olduğu edimi özel bir nedenle yerine getirmemesini doğuran bir haktır. Defilere, iş mahkemelerinde ilk duruşmada ileri sürülen zamanaşımı defi örnek gösterilebilir. Zamanaşımı, alacak hakkının süresinde kullanılmaması neticesinde dava edilebilme özelliğinin ortadan kalkmasını ifade eder. Zamanaşımı alacak hakkını sonlandırmayıp, onu eksik bir borç haline dönüştürmekte, daha açık ifadeyle alacağın istenebilirliğini ortadan kaldırmaktadır. Borçlu, zamanaşımının varlığını yasada gösterilen süre ve usul içinde yapması gerekir. Hâkim görevi gereği kendiliğinden zamanaşımını göz önünde tutamaz (Yargıtay 7. Hukuk Dairesi, 2013; Erdağ, 2017). Dolayısıyla bilirkişi, taraflarca usulüne uygun ve süresinde ileri sürülen zamanaşımını dikkate alarak raporunu düzenlemelidir.

\subsubsection{Belgelerin Dikkate Alınması}

4857 sayılı İş Kanunu m.37'ye göre, işveren iş yerinde ya da banka yoluyla yaptığı ödemelerde işçiye ücret hesabını gösterir imzalı veya işyerinin özel işaretini barındıran bir pusula vermekle yükümlüdür. Yine bu pusulada, ödemenin günü ve 
ait olduğu dönemi, fazla çalışması, hafta tatili, bayram ve genel tatil ücretleri gibi asıl ücrete yapılan her tür eklemelerin tutarı, vergi, sigorta primi, avans mahsubu, nafaka ve icra gibi her kesintilerin ayrı ayrı gösterilmesini zorunlu tutmuştur.

İş yargısında yürürlükte olan iş kanunu, toplu iş sözleşmeleri ve hizmet akitleri öncelikli olarak dikkate alınmalıdır. İnceleme ve hesaplamalarda; bordrolar, yıllık izin defterleri, özlük dosyası, SGK sicil dosyası, ödeme makbuzları, ibranameler, tanık beyanları, tutanaklar, puantaj listeleri gibi belgeler çok önemlidir (Bozkurt, 2009: 119). Örneğin; yıllık izin sürelerinin hesabında varsa öncelikle toplu iş sözleşmeleri veya bireysel iş sözleşmesi şayet bunlar yoksa iş kanununda öngörülen izin süreleri göz önünde bulundurulmalıdır.

\subsubsection{Takdiri İndirim (Hakkaniyet İndirimi)}

İş mahkemelerinde işçi alacaklarıyla ilgili davalarda davacının fazla çalışma yaptığının tanık beyanlarına göre belirlendiği ve özellikle fazla çalışmanın uzun bir süre için hesaplanması ve miktarın yüksek çıkması durumunda mahkemece toplam tutardan uygun bir indirim yapılmasıdır. Esasında bu uygulama iş kanunu veya mevzuatla düzenlenmiş olmayıp, Yargıtay’ın kararları ile istikrarlı hale gelmiştir (www.isvesosyalguvenlik.com). Bazı mahkemelerce uygulanan \%50 takdiri indirim oranı Yargıtay tarafından yüksek bulunmuş, hesaplanan fazla çalışma miktarına göre takdir edilmesi, hakkın özünü ortadan kaldıracak oranda bir indirime gidilmemesi gerektiği vurgulanmıştır (Yargıtay 9. Hukuk Dairesi, 2017). Bu yüzden takdiri indirim oranı uygulamada daha çok \%25-30 arasındadır.

\section{LITERATÜR TARAMASI}

Literatürde muhasebe alanında bilirkişiliği uygulamalı olarak ele alan çalışmalar fazla olmasa da teorik açıdan inceleyen ve bilirkişilikle ilgili muhasebe meslek mensuplarının görüşlerini ve sorunlarını sorgulayan pek çok araştırma bulunmaktadır. Bu anlamda yapılan yerli ve yabancı çalışmalardan bazıları aşağıda siralanmıştır.

Utku ve Kurtcebe (2019) tarafından yapılan çalışmada, muhasebe meslek mensuplarının bilirkişilik temel eğitimi ile ilgili görüşleri belirlemesi amaçlanmıştır. Denizli Serbest Muhasebeci Mali Müşavirler Odası'nda (SMMMO) gerçekleştirilen 
araştırmada katılımcıların bilirkişilik eğitimine ilişkin memnuniyet düzeyinin oldukça yüksek olduğu ancak eğitim süresi ve bilgi ihtiyacı karşılama düzeyinin bir o kadar düşük olduğu tespit edilmiştir.

Meriç, Erkuş ve Kaygusuzoğlu (2016), bilirkişilik kurumu ile ilgili sorunları ele almak amacıyla yaptıkları çalışmada, Serbest Muhasebeci Mali Müşavirlere (SMMM) ve hâkimlere yüz yüze anket uygulamışlardır. Araştırmada; bilirkişilik müessesesinde önemli sorunlar olduğu ancak bu sorunların bilirkişilik yapan SMMM'ler için geçerli olmadığı sonucuna varmışlardır. Yine de SMMM'lerin bilirkişilik müessesesinin daha etkin hale getirilmesi için gerekli adımların atılması yönünde beklenti içinde oldukları ifade etmişlerdir.

Kısacık (2018) çalışmasında, 2016 yılında yürürlüğe konan 6754 sayılı Bilirkişilik Kanunu doğrultusunda adli muhasebenin bir kolu olan muhasebe bilirkişili mesleğini incelemiştir. Çalışmanın sonucunda bilirkişiliğin adli muhasebe mesleğinde önemli olduğunu, muhasebe bilirkişilerin hukuki davalara yarg1 mensuplarına hizmet verdiklerini, bilirkişi olarak görevlendirilen meslek mensuplarının kendilerini geliştirebildikleri ölçüde hizmet kalitelerinin artacağını ve 6754 sayılı Bilirkişilik Kanunu'nun bilirkişilik müessesesini daha işlevsel hale getireceğini vurgulamıştır.

Aksu, Uğur ve Çukacı (2008), adlî muhasebe mesleğinin faaliyet alanlarından birisi olan bilirkişilik müessesesini tanıtmak amacıyla yaptıkları çalışmada, muhasebe bilirkişilerin, uyuşmazlıkların çözümünde hâkimlere yardımcı olmalarının yanında hile ve suçların önlemesinde alınacak tedbirlere yönelik sistemlerin kurulmasındaki önemine de vurgu yapmışlardır.

Brennan (2005) çalışmasında, İngiltere ve Kuzey Amerika perspektifinde muhasebe uzmanlarının uyuşmazlıkların çözümünde bilirkişilik rollerini incelemiştir. Bilirkişilik görevinin diğer muhasebe görevlerinden farklı standartlara sahip olduğunu belirterek, bilirkişi delillerinin nitelikleri ve önemine değinmiştir.

Sanchez ve Zhang (2012) bilirkişilerin niteliklerini inceledikleri çalışmalarında, birçok davada bilirkişilere başvurulduğu, davaların çözümlenmesinde bilirkişilerin çok önemli rol oynadığını belirtmişlerdir. Bu bağlamda Enron ve Healthsouth olarak 
bilinen iki yüksek profilli dolandırıcılık davasının çözüme kavuşturulmasında bilirkişilerin önemini ortaya koymuşlardır.

\section{4. ÖRNEK UYGULAMA}

$\mathrm{Bu}$ bölüm iş mahkemesinde işçi ve işveren arasında görülen örnek bir alacak davasında ilave tediye, fazla mesai ve yıllık izin gibi alacakların hesaplanmasına ilişkin uygulamadan oluşmaktadır. Bu kapsamda dava dosyası hakkında özet bilgiler verildikten sonra mahkemenin bilirkişiden cevaplandırmasını istediği konulardan her biri ayrı başlıklar altında verilecektir.

\section{1. Çalışmanın Amacı, Önemi ve Yöntemi}

Uyuşmazlıkların çözümünde mali konulara ilişkin mahkemelerin ihtiyaç duyduğu bilirkişilik desteği muhasebe meslek mensuplarınca verilmektedir. Bilirkişi bölge kurullarında bilirkişi listelerine kayıtlı olarak görev yapan meslek mensuplarının sayısı oldukça fazladır. Muhasebe bilirkişiliği ya da diğer söylemle hesap bilirkişiliği ihtiyacı hemen hemen tüm dava türlerinde görülebilmektedir. Ancak yapılacak hesaplamalar diğer davalara nazaran iş mahkemelerinde görülen alacak davalarında daha kapsamlı olabilmekte, hatta mahkemeler bir davada birkaç bilirkişiye başvurabilmektedir. Bilirkişiler tarafından yapılan hatalı hesaplamalar ve yanlış uygulamalar bazen verilen kararların bozulmasına, yargılama sürecinin uzamasina neden olabilmektedir.

Muhasebe bilirkişileri tarafından hazırlanan raporlarda belli standartlar olsa da farklı bilirkişiler tarafından yapılan hesaplamalar farklı sonuçlar ortaya koymakta, göz önünde bulundurulan etkenlere bağlı olarak rakamlar birbirini tutmamaktadır. Bu doğrultuda yapılan çalışmada, işçi ve işveren arasında görülen alacak davalarında yapılacak hesaplamalarda göz önünde bulundurulacak hususların belirlenmesi, hazırlanacak bilirkişi raporunun şekli ve içeriği hakkında genel bir çerçeve oluşturulması amaçlanmaktadır. Literatürde muhasebe bilirkişiliği üzerine teorik çalışmalar bulunmakta ancak uygulamaya dönük çalışmalara rastlanmamaktadır. Bu yönü ise çalışmanın önemine vurgu yapmaktadır.

Çalışma, dava konusu alacakların ilgili mevzuat ve kanunlar, iş sözleşmeleri, dosyada mevcut belge, bilgi ve yerinde incelemeler sonucu elde edilen diğer evraklar 
doğrultusunda her bir alacak kaleminin ayrı ayrı değerlendirilmesi ve hesaplanması yöntemiyle yapılmıştır. Çalışmada geçen kişi ve kurum isimleri kişisel verilerin korunmasına yönelik hassasiyetten dolayı değiştirilmiştir. Yine araştırma ve kullanılan veriler 2020 yılı öncesine ait olduğu için etik kurul iznine ihtiyaç duyulmamiştır.

\subsection{Davayla İlgili Açıklamalar}

Dava, kamu kurumu niteliğinde $\mathrm{ABC}$ belediyesi ile bu belediyeden emekli olan işçisi Ahmet $X$ arasındadır. 01.07.2000 tarihinde temizlik işçisi olarak işe başlayan Ahmet X'in 14.05.2013 tarihinde emeklilik nedeniyle iş akdi fesh edilmiştir. Belediyede çalıştığı dönemde hafta tatili yapmadığını, ulusal bayramlarda ve genel tatillerde çalıştığını, ilave tediyelerinin ödenmediğini ve bazı yıllık izinlerini kullanamadığını belirtmiş, fazlaya dair alacaklarının saklı kalması koşuluyla açtığı davada, aynı dönem çalıştığı birkaç iş arkadaşının şahitliği ile fazla çalışmalarını ispat etmiştir. İş mahkemesinde yapılan yargılama sonucu davacı lehine karar verilmiş, bilirkişi raporunun düzenlenmesinde ki eksiklikler ve yanlış hesaplanan alacak tutarları nedeniyle karar üst mahkemece bozulmuştur. Davalı işyerinin kamu statüsünde olması dolayısıyla bilgi, belge ve kayıtların düzenli tutulması gerektiğine vurgu yapan üst mahkeme, yargilamanın yeniden yapılmasını ve uzman bir bilirkişinin görevlendirilerek karara varılması gerektiğini belirtmiştir. Bunun üzerine ilgili mahkeme, şahitlerle ispat edilen fazla çalışmaları ve diğer alacakların hesaplanması için bilirkişiye başvurmuş, bilirkişiden yerinde inceleme yapmasını istemiştir.

\subsection{Mahkeme Tarafından Bilirkişiden İstenilen İnceleme ve Tespitler}

Davalı ABC Belediyesi kayıtlarının yerinde incelenerek, davacı Ahmet X'in çalışma saatlerini gösterir;

1. Nöbet çizelgeleri, puantaj kayıtları, sosyal yardım alacağına ilişkin ödeme belgeleri, İlave tediye alacağına ilişkin tüm belgeler, hesap özetleri gibi belgelerin incelenmesi ve ödemelerin ne şekilde yapıldığının belirlenmesi,

2. Davacının dava konusu alacaklarının bulunup bulunmadığının tespit edilmesidir. 


\subsection{Bilirkişi Tarafından Dosya ve Yerinde Yapılan İnceleme ve Tespitler}

Kayıt ve belgelerin incelenmesinde; aritmetik doğruluklar, yetkili imzaların olup olmadığı, ardışık sıra numaralarını ve tarihleri izleyip izlemedikleri, doğru dosyalanıp dosyalanmadıkları gibi konular araştırılmaktadır. Bu araştırma ve inceleme iki şekilde yapılabilmektedir (Selimoğlu vd., 2014: 146);

a) Kayıtların ileriye doğru incelenmesi

b) Kayıtların geriye doğru incelenmesi

Dava konusu alacakların uzun bir dönemi kapsamasından dolayı, bilinenden bilinmeyene doğru yani kayıtların geriye doğru incelenmesi sonuçların ortaya konulması açısından daha rasyoneldir. Bu nedenle belge ve kayıtlar, davacı Ahmet $X^{\prime}$ in emekliye ayrılma tarihi olan 14.05 .2013 'ten itibaren geriye doğru incelenmiştir.

Dava dosyasında iddia edilen alacaklara ilişkin en önemli belge niteliğinde olan ücret bordroları mevcut olup yapılan incelemelerde bordrolarda fazla çalışma ve diğer alacaklara ilişkin herhangi bir ibareye rastlanılmamıştır. Yine dosya kapsamında işçi sendikası ile ilgili belediye arasında imzalanan toplu iş sözleşmeleri bulunmakta olup davacının çalıştığı sürelerde bu toplu iş sözleşmelerinin yürürlükte olduğu tespit edilmiştir. Bunlarla birlikte davacı işçinin işe giriş tarihi, iş akdinin feshi, maaş ödeme dekontları veya imzalı maaş alındı cetvelleri gibi belgeler bulunmaktadır. Dosya da iddia edilen alacaklar üzerine başkaca herhangi bir belge ve bilgiye rastlanmamıştır.

Davalı ABC Belediyesine, dava konusu kayıt ve belgelerin hazırlanması ve ilgili görevlilerin işyerinde bulunması amacıyla 10 gün önceden haber verilmiş, alınan randevu doğrultusunda 15.03.2019 tarihinde yerinde inceleme yapmak üzere ilgili birime gidilmiştir. İlgili birimde yapılan incelemelerde davalı belediyenin kamu kurum ve kuruluşu statüsünde olmasına rağmen 2014 y1lından daha eski tarihli evrakların ve kayıtlarının bulunmadığı, ancak ilave tediyelerle ilgili bilgisayarda kayıtlı bazı bordroların ve bunlara ait banka ödeme belgelerinin olduğu muhasebe ve personel görevlilerince ifade edilmiş birer nüshaları ibraz edilmiştir. Davalı belediye tarafından ibraz edilen ilave tediyelere ilişkin belgeler aşağıda sunulmuştur. 
1) 2013 yılı 1. Dönem ilave tediyenin ödendiğine dair banka hesap belgesi,

2) 2012 y1lı 1 ve 2. Dönem ilave tediye bordroları ve ödendiğine dair banka hesap belgeleri,

3) 2011 y1lı 1 ve 2. Dönem ilave tediye bordrosu ve ödendiğine dair banka hesap belgesi,

4) 2010 yılı 1, 2, 3 ve 4. Dönem ilave tediye bordroları ve ödendiğine dair banka hesap belgesi,

5) 2009 y1lı 3 ve 4 . Dönem ilave tediye bordrosu ve ödendiğine dair banka hesap belgesi,

6) 2006 yılı 1, 3 ve 4. Dönem ilave tediye bordroları (davacı tarafından alındığına dair imzalı)

7) 2004 yılı 1. Dönem ilave tediye bordrosu (davacı tarafından alındı̆̆ına dair imzalı)

Yukarı sayılan belgeler haricinde nöbet çizelgeleri, puantaj kayıtları, Sosyal yardım alacağına ilişkin ödeme belgeleri, diğer ilave tediyelere ilişkin belge, hesap özetleri ve başkaca herhangi bir kayıt ve belge ibraz edilememiştir (mevcut değil).

Görevlilerin ifadeleri ve sunulan ilave tediye ödeme belgelerinden anlaşıldı $\breve{g} 1$ üzere ödemeler 2006 yılına kadar elden, bu tarihten 2013 yılına kadar Z Bankası T Şubesi aracığıyla, 2013 yılından sonra ise aynı bankanın M Şubesinden yapıldığı belirlenmiştir.

Davacı ve davalı arasında, davaya konu olan alacakların her biri hem yerinde hem de dava dosyası kapsamında ele alınmış, yapılan inceleme, tespit ve hesaplamalar aşağıda sıralanmıştır.

\subsection{1. İlave Tediye Alacaklarına İlişkin İnceleme ve Tespitler}

İlave tediye alacaklarına ilişkin yapılacak ilk inceleme davacı işçinin ilave tediye ödenecekler kapsamına girip girmediğidir. Bu anlamda ilave tediye, 6772 sayılı Devlet ve Ona Bağlı Müesseselerde Çalışan İşçilere İlave Tediye Yapılması Hakkındaki Kanun ile düzenlenmiştir. Belediyelerde işçi statüsünde çalışanlarda 
ilave tediye ödenecekler kapsamına girmektedir. İlave tediye yılda 52 gün üzerinden hesaplanmakla birlikte $13+13+13+13$ olmak üzere 4 taksit halinde ödenmektedir. Bununla birlikte ilave tediye hesaplanması için ilgili işçinin işe giriş tarihi, bir günlük çalışma ücreti ve iş sözleşmesini fesih tarihi gibi bilgiler önemlidir. Bu yönde yapılan incelemelerde dava dosyasında işe başlama ve iş sözleşmesinin fesih tarihi belirlenmiş, ayrıca her döneme denk gelen günlük ücret tutarı tespit edilmiştir. Excel formatında oluşturulan tablo yardımıyla ilgili çalışanın işe giriş tarihinden emekli olduğu tarihi kadar ilave tediyeleri hesaplanmıştır.

Sunulan ilave tediye bordroları ile banka ödeme belgeleri karşılaştırılmış, ödenen ilave tediyeler tespit edilerek daha önceden belirlenen ilave tediye alacağından düşülmüştür. Ödenen ve ödemesi ibraz edilemeyen ilave tediyeler tablo 1 'de sunulmuştur.

Tabloda ödenmiş görülen ilave tediyeler kesintilerden sonra net tutarlardır. Bordro ve banka hesap belgeleri dosyaya eklenmiştir. Diğer ilave tediye bordroları ve ödemelerine ilişkin herhangi bir kayıt ve belge ibraz edilmemiştir (mevcut değil). 
Tablo 1. İlave Tediye Alacaklarına İlişkin Hesaplama

\begin{tabular}{|c|c|c|c|c|c|c|}
\hline \multicolumn{7}{|c|}{ İLAVE TEDIYYE HESAPLAMA } \\
\hline \multicolumn{2}{|c|}{ DÖNEM } & \multirow{2}{*}{$\begin{array}{c}\text { YEVMİYE } \\
3,96\end{array}$} & \multirow{2}{*}{$\begin{array}{c}\text { İLAVE } \\
\text { GÜN } \\
\text { (TL) }\end{array}$} & \multirow{2}{*}{ 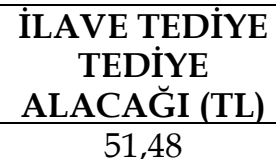 } & \multirow{2}{*}{$\begin{array}{l}\text { ÖDENEN } \\
\text { NET (TL) } \\
\end{array}$} & \multirow{2}{*}{$\begin{array}{c}\text { KALAN } \\
\text { (TL) }\end{array}$} \\
\hline & 3.Dönem & & & & & \\
\hline 2000 & 4.Dönem & 3,96 & 13 & 51,48 & & 51,48 \\
\hline \multirow{4}{*}{2001} & 1.Dönem & 6,41 & 13 & 83,33 & & 83,33 \\
\hline & 2.Dönem & 6,41 & 13 & 83,33 & & 83,33 \\
\hline & 3.Dönem & 6,41 & 13 & 83,33 & & 83,33 \\
\hline & 4.Dönem & 6,41 & 13 & 83,33 & & 83,33 \\
\hline \multirow{4}{*}{2002} & 1.Dönem & 6,41 & 13 & 83,33 & & 83,33 \\
\hline & 2.Dönem & 7,00 & 13 & 91,00 & & 91,00 \\
\hline & 3.Dönem & 7,00 & 13 & 91,00 & D & 91,00 \\
\hline & 4.Dönem & 7,00 & 13 & 91,00 & 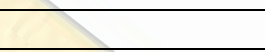 & 91,00 \\
\hline \multirow{4}{*}{2003} & 1.Dönem & 7,00 & 13 & 91,00 & 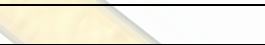 & 91,00 \\
\hline & 2.Dönem & 10,92 & 13 & 141,96 & 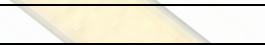 & 141,96 \\
\hline & 3.Dönem & 10,92 & 13 & 141,96 & 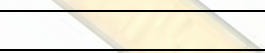 & 141,96 \\
\hline & 4.Dönem & 13,10 & 13 & 170,30 & 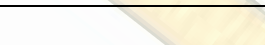 & 170,30 \\
\hline \multirow{4}{*}{2004} & 1.Dönem & 16,21 & 13 & 210,73 & 177,98 & 0,00 \\
\hline & 2.Dönem & 16,21 & 13 & 210,73 & D & 210,73 \\
\hline & 3.Dönem & 18,05 & 13 & 234,65 & & 234,65 \\
\hline & 4.Dönem & 18,05 & 13 & 234,65 & $2=$ & 234,65 \\
\hline \multirow{4}{*}{2005} & 1.Dönem & 20,78 & 13 & 270,14 & 7 & 270,14 \\
\hline & 2.Dönem & 20,78 & 13 & 270,14 & r & 270,14 \\
\hline & 3.Dönem & 20,78 & 13 & 270,14 & Z & 270,14 \\
\hline & 4.Dönem & 20,78 & 13 & 270,14 & & 270,14 \\
\hline \multirow{4}{*}{2006} & 1.Dönem & 22,96 & 13 & 298,48 & 228,00 & 0,00 \\
\hline & 2.Dönem & 22,96 & 13 & 298,48 & & 298,48 \\
\hline & 3.Dönem & 22,96 & 13 & 298,48 & 251,91 & 0,00 \\
\hline & 4.Dönem & 22,96 & 13 & 298,48 & 251,92 & 0,00 \\
\hline \multirow{4}{*}{2007} & 1.Dönem & 24,00 & 13 & 312,00 & & 312,00 \\
\hline & 2.Dönem & 24,00 & 13 & 312,00 & & 312,00 \\
\hline & 3.Dönem & 26,90 & 13 & 349,70 & & 349,70 \\
\hline & 4.Dönem & 26,90 & 13 & 349,70 & & 349,70 \\
\hline \multirow{4}{*}{2008} & 1.Dönem & 27,47 & 13 & 357,11 & & 357,11 \\
\hline & 2.Dönem & 27,47 & 13 & 357,11 & & 357,11 \\
\hline & 3.Dönem & 31,93 & 13 & 415,09 & & 415,09 \\
\hline & 4.Dönem & 31,93 & 13 & 415,09 & & 415,09 \\
\hline \multirow{4}{*}{2009} & 1.Dönem & 33,23 & 13 & 431,99 & & 431,99 \\
\hline & 2.Dönem & 33,23 & 13 & 431,99 & & 431,99 \\
\hline & 3.Dönem & 34,53 & 13 & 448,89 & 304,30 & 0,00 \\
\hline & 4.Dönem & 34,53 & 13 & 448,89 & 304,30 & 0,00 \\
\hline \multirow{4}{*}{2010} & 1.Dönem & 34,73 & 13 & 451,49 & 321,62 & 0,00 \\
\hline & 2.Dönem & 34,73 & 13 & 451,49 & 321,63 & 0,00 \\
\hline & 3.Dönem & 37,15 & 13 & 482,95 & 333,18 & 0,00 \\
\hline & 4.Dönem & 37,15 & 13 & 482,95 & 333,18 & 0,00 \\
\hline \multirow{4}{*}{2011} & 1.Dönem & 39,59 & 13 & 514,67 & 378,59 & 0,00 \\
\hline & 2.Dönem & 39,59 & 13 & 514,67 & 378,59 & 0,00 \\
\hline & 3.Dönem & 41,17 & 13 & 535,21 & & 535,21 \\
\hline & 4.Dönem & 41,17 & 13 & 535,21 & & 535,21 \\
\hline & 1.Dönem & 41,17 & 13 & 535,21 & 376,64 & 0,00 \\
\hline & 2.Dönem & 41,17 & 13 & 535,21 & 376,64 & 0,00 \\
\hline 2012 & 3.Dönem & 43,76 & 13 & 568,88 & & 568,88 \\
\hline & 4.Dönem & 43,76 & 13 & 568,88 & & 568,88 \\
\hline 2013 & 1.Dönem & 45,57 & 13 & 592,41 & 424,11 & 0,00 \\
\hline 2013 & 2.Dönem & 45,57 & 6 & 273,42 & & 273,42 \\
\hline & & & & İlave Te & liye Brüt Alacağı & $9.610,28$ \\
\hline
\end{tabular}

Kaynak: Yazar tarafından üretilmiştir. 


\subsubsection{Hafta tatili Alacaklarına İlişkin İnceleme ve Tespitler}

4857 sayılı İş Kanunu uyarınca çalışma süresi haftada en fazla 45 saattir. Fazla çalışma, mevzuatta belirlenen koşullar çerçevesinde haftalık 45 saati aşan çalışmalardır. Fazla çalışma için işçinin onayının alınması gerekir. Fazla çalışma süresinin toplamı bir yılda 270 saatten çok olamaz. Çalışılan her bir saat fazla çalışma için verilecek ücret, normal çalışma saat ücretinin \%50 fazlasıdır. Fazla sürelerle çalışma ise, sözleşmede haftalık çalışma süresinin 45 saatin altında belirlendiği durumlarda, 45 saate kadar yapılan çalışmalardır. Fazla sürelerle çalışmalarda, çalışılan her bir saat fazla çalışma karşılığında verilecek ücret, normal çalışmadaki saat ücretinin \%25 fazlasıdır (Çelik ve Bingöl, 2016).

Yukarıdaki açıklamalar ışığında kamu kurumu statüsünde olan söz konusu belediyede haftalık çalışma süresi 4857 sayılı İş Kanunu'na göre 45 saattir. Bununla birlikte yetkili işçi sendikası ile belediye arasında imzalanan ve yürürlükte olan toplu iş sözleşmesinde fazla çalışmalara ilişkin maddelerde hafta tatillerinde çalıştırılacak işçilere 3 gündelik ve ertesi gün izin verileceği belirlenmiştir. Bu bağlamda hesaplamalarda toplu sözleşme hükümleri geçerli olacaktır.

Hafta tatilinde yapılan fazla çalışmalar her türlü delille ve tanıklarla ispat edilebilir. İspat için iş yeri kayıtları, özellikle iş yerine girişi ve çıkışı gösteren belgeler, işyeri iç yazışmaları ve benzeri belgeler delil niteliği taşımaktadır. Ancak bu çalışmalar yazılı belge ve kayıtlarla kanıtlanamaması durumunda tarafların dinletmiş oldukları tanık beyanları ile sonuca varılabilir. Yine herkes tarafından bilinen bazı vakıalarda göz önüne bulundurulabilir. İşçinin fiilen yaptığı işin niteliği ve yoğunluğuna göre fazla çalışma olup olmadığı ortaya konulabilir. (Yargıtay Hukuk Genel Kurulu, 2015). Diğer yandan davalı ABC Belediyesi, davacının çalışmalarını gösteren nöbet çizelgeleri, puantaj kayıtları, işyeri giriş çıkış belgeleri ve işyeri iç yazışmaları gibi herhangi bir kayıt ve belge ibraz edememiştir (mevcut değil).

Davacı hafta tatili çalışmalarını aynı dönem birlikte çalıştığı kişilerin tanık beyanları ile ispatlamıştır. Yine yerinde incelemede, her ilçede haftada bir gün kurulan pazar yerinin, ABC ilçesinde pazartesi günleri kurulduğu, bu nedenle 
işçilerin pazara hazırlık amacıyla pazar günleri tam gün çalıştıkları, cumartesi günlerinde ise tam gün izin yaptıkları belediye görevlilerince ifade edilmiştir. Yerleşik hale gelen bu uygulamayla ilgili toplu iş sözleşmelerinde herhangi bir hüküm bulunmamaktadır. Bu nedenle davacının mahkeme huzurunda şahitlerle ispatladığı hafta tatili alacak tutarı, dava dosyasında mevcut ücret bordroları üzerinde görülen saat ücreti ile hesaplanarak Tablo 2'de sunulmuştur.

Tablo 2. Hafta Tatili Alacaklarına İlişkin Hesaplama

\begin{tabular}{|c|c|c|c|c|}
\hline \multicolumn{5}{|c|}{ HAFTA TATİLİ HESAPLAMA } \\
\hline DÖNEMİ & $\begin{array}{c}\text { GÜNLÜK } \\
\text { BRÜT ÜCRET } \\
\text { (TL) }\end{array}$ & $\begin{array}{l}4 \text { GÜNDELIK } \\
\text { ÜCRET } \\
\text { (TL) }\end{array}$ & \begin{tabular}{|l} 
ÇALIŞAN \\
HAFTA \\
SAYISI \\
\end{tabular} & $\begin{array}{c}\text { HAKEDİLEN } \\
\text { HAFTA TATİLI } \\
\text { BRÜT ÜCRETI (TL) }\end{array}$ \\
\hline $01.07 .2000-31.12 .2000$ & 3,96 & 15,84 & 26 & 411,84 \\
\hline $01.01 .2001-31.03 .2002$ & 6,41 & 25,64 & 12 & 307,68 \\
\hline $01.04 .2002-28.02 .2003$ & 7,00 & 28,00 & 47 & $1.316,00$ \\
\hline $01.03 .2003-31.12 .2003$ & 10,92 & 43,68 & 43 & $1.878,24$ \\
\hline $01.01 .2004-31.05 .2004$ & 13,10 & 52,40 & 21 & $1.100,40$ \\
\hline $01.06 .2004-31.12 .2004$ & 16,21 & 64,84 & 29 & $1.880,36$ \\
\hline $01.01 .2005-30.06 .2006$ & 18,05 & 72,20 & 24 & $1.732,80$ \\
\hline $01.07 .2006-31.12 .2006$ & 20,78 & 83,12 & 23 & $1.911,76$ \\
\hline $01.01 .2007-30.06 .2007$ & 22,96 & 91,84 & 26 & $2.387,84$ \\
\hline $01.07 .2007-30.11 .2007$ & 24,00 & 96,00 & 24 & $2.304,00$ \\
\hline $01.12 .2007-30.06 .2008$ & 26,90 & 107,60 & 30 & $3.228,00$ \\
\hline $01.07 .2008-31.12 .2008$ & 27,47 & 109,88 & 23 & $2.527,24$ \\
\hline $01.01 .2009-30.06 .2009$ & 31,93 & 127,72 & 26 & $3.320,72$ \\
\hline $01.07 .2009-30.06 .2010$ & 33,23 & 132,92 & 49 & $6.513,08$ \\
\hline $01.07 .2010-31.12 .2010$ & 37,15 & 148,60 & 23 & $3.417,80$ \\
\hline $01.01 .2011-30.06 .2011$ & 39,59 & 158,32 & 24 & $3.800,64$ \\
\hline $01.07 .2011-31.05 .2012$ & 41,17 & 164,68 & 44 & $7.245,92$ \\
\hline $01.06 .2012-31.12 .2012$ & 43,76 & 175,04 & 28 & $4.901,12$ \\
\hline $01.01 .2013-14.05 .2013$ & 45,57 & 182,28 & 13 & $2.369,64$ \\
\hline$x+2+2$ & +4 & plam Hafta Ta & Brüt Ücreti & $52.555,08$ \\
\hline 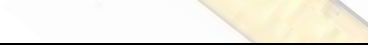 & (f & $\% 30 \mathrm{~T}$ & diri İndirim & $15.766,52$ \\
\hline 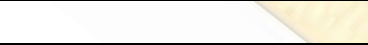 & 2 & Hafta Tatili & rüt Alacağı & $36.788,56$ \\
\hline
\end{tabular}

Kaynak: Yazar tarafından üretilmiştir.

Davacının izinli ve raporlu olduğu tarihler hesaplamaya dâhil edilmemiştir Hafta tatili çalışması tanık beyanına göre yapıldığı için \%30 takdiri indirim yapilmıştır.

\subsubsection{Ulusal Bayram Genel Tatil (UBGT) Alacağına İlişkin İnceleme ve}

\section{Tespitler}

Davalı ABC Belediyesi davacının çalışmalarını gösterir nöbet çizelgeleri, puantaj kayıtları, işyeri giriş çıkış belgeleri ve işyeri iç yazışmaları veya bu 
çalışmalara ilişkin ödeme belgeleri gibi ispat niteliğinde herhangi bir kayıt ve belge ibraz edememiştir (mevcut değil).

Davacının ulusal bayram ve genel tatil (UBGT) günlerinde çalıştığ1 yönünde iddiasını tanık beyanı ile ispat ettiği bilinmektedir. Dosya kapsamında bulunan Toplu İş Sözleşmeleri ilgili maddelerinde "ulusal bayram ve genel tatil günlerinde çalışan işçilere üç yevmiye ilave ücret ödeneceği, arife günlerine rastlayan tam günlük çalışmalarda iki yevmiye ödeneceği” hüküm altına alınmıştır.

Tanık beyanlarında resmi bayramlarda çalışıldığı, dini bayramlarda ise bir veya iki gün izin yapıldığı ve 2010 yılından sonra resmi ve dini bayramlarda çalışılmadığı ifade edilmiştir. Bu nedenle hesaplamalar yapılırken davacının işe başladığı tarih olan Temmuz 2000'den 30 Haziran 2010 tarihleri temel alınmıştır. UBGT alacağına ilişkin hesaplamalar tablo 3'te sunulmuştur.

Tablo 3. Ulusal Bayram Genel Tatil (UBGT) Alacaklarına İlişkin Hesaplama

\begin{tabular}{|c|c|c|c|c|}
\hline \multicolumn{5}{|c|}{ UBGT HESAPLAMA } \\
\hline DÖNEMİ & $\begin{array}{c}\text { GÜNLÜK } \\
\text { BRÜT ÜCRET } \\
\text { (TL) }\end{array}$ & $\begin{array}{l}3 \text { GÜNDELIKK } \\
\text { ÜCRET } \\
\text { (TL) }\end{array}$ & $\begin{array}{l}\text { ÇALIŞILAN } \\
\text { UBGT } \\
\text { SAYISI }\end{array}$ & \begin{tabular}{|c} 
HAKEDİLEN \\
UBGT \\
BRÜT ÜCRETİ (TL)
\end{tabular} \\
\hline $01.07 .2000-31.12 .2000$ & 3,96 & 11,88 & 1 & 11,88 \\
\hline $01.01 .2001-31.12 .2001$ & 6,41 & 19,23 & 3,5 & 67,31 \\
\hline $01.01 .2002-31.12 .2002$ & 7,00 & 21,00 & 8,5 & 178,50 \\
\hline $01.01 .2003-31.12 .2003$ & 10,92 & 32,76 & 5,5 & 180,18 \\
\hline $01.01 .2004-31.05 .2004$ & 13,10 & 39,30 & 5 & 196,50 \\
\hline $01.06 .2004-31.12 .2004$ & 16,21 & 48,63 & 3,5 & 170,21 \\
\hline $01.01 .2005-30.06 .2005$ & 18,05 & 54,15 & 9 & 487,35 \\
\hline $01.07 .2005-31.12 .2005$ & 20,78 & 62,34 & 3,5 & 218,19 \\
\hline $01.01 .2006-31.12 .2006$ & 22,96 & 68,88 & 4 & 275,52 \\
\hline $01.012007-30.06 .2007$ & 24,00 & 72,00 & 2,5 & 180,00 \\
\hline 01.07 .2007 - 31.12.2007 & 26,90 & 80,70 & 3,5 & 282,45 \\
\hline $01.01 .2008-30.06 .2008$ & 27,47 & 82,41 & 7 & 576,87 \\
\hline $01.07 .2008-31.12 .2008$ & 31,93 & 95,79 & 3 & 287,37 \\
\hline $01.01 .2009-30.06 .2010$ & 33,23 & 99,69 & 7,5 & 747,68 \\
\hline \multicolumn{4}{|c|}{$\begin{array}{r}\text { Toplam UBGT Alacağ } 1 \\
\% 30 \text { Takdiri İndirim }\end{array}$} & $3.860,01$ \\
\hline \multicolumn{4}{|c|}{ \%30 Takdiri İndirim } & $1.158,00$ \\
\hline \multicolumn{4}{|c|}{ Talep Edilebilecek UBGT Brüt Ücreti } & $2.702,01$ \\
\hline
\end{tabular}

Kaynak: Yazar tarafından üretilmiştir.

UBGT çalışması tanık beyanına göre yapıldı̆̆ı için \%30 takdiri indirim yapılmıştır. 


\subsubsection{Yıllık İzin Alacağına İlişkin İnceleme ve Tespitler}

Yıllık ücretli izin hesaplamalarında göz önünde bulundurulacak temel göstergelerden birisi yürürlükte olan iş kanunudur. Davacının işe başladığı tarih olan Temmuz 2000 yılında 1475 sayılı İş Kanunu yürürlüktedir. Söz konusu kanun kapsamına giren işyerlerinde çalışan işçilere, deneme süresi de dâhil olmak üzere işe girildiği tarihten itibaren en az bir yıl çalışmış olmak kaydıyla hizmet sürelerine göre ücretli yıllık izin verilmesi gerekmektedir. Davacının Temmuz 2001 yılında hak ettiği ilk ücretli izni kanun uyarınca 12 gündür. Her ne kadar 2003 yılı itibariyle 4857 sayılı İş Kanunu yürürlüğe girse de 2001 yılından itibaren yapılan toplu iş sözleşmelerinde bir yılı dolduran işçilere 30 gün ücretli izin verileceği kararlaştırılmıştır. Bu nedenle hesaplamalarda ilk ücretli izni 12 gün üzerinden daha sonrakiler toplu iş sözleşmesi gereği 30 gün üzerinden hesaplanmıştır.

Davalı ABC Belediyesi, davacının hak ettiği yıllık izin sürelerini kullandığını veya kullanmadıysa bu sürelerin ödendiğini gösteren herhangi bir kayıt ve belge ibraz edememiştir (mevcut değil). Bununla birlikte dosya kapsamında bulunan yıllık izin belgelerinden davacının kullandığı yıllık izin süreleri belirlenmiş ve dökümü aşağıda çıkarılmıştır.

İzine Çıkıș Tarihi Kullanılan İzin Süresi $\quad \underline{\text { Rapor Bașlang1ç Tarihi }}$ Raporlu Gün Sayısı

$\begin{array}{llll}23.12 .2004 & 20 \text { Gün } & 12.03 .2006 & 45 \text { Gün } \\ 15.11 .2006 & 20 \text { Gün } & \\ 03.09 .2008 & 20 \text { Gün } & \\ 17.12 .2009 & 20 \text { Gün } & \\ 06.12 .2010 & 30 \text { Gün } & \\ 24.11 .2011 & 20 \text { Gün } & \\ 17.04 .2012 & 6 \text { Gün } & \\ 05.07 .2012 & 10 \text { Gün } & \\ 12.03 .2013 & \text { 35 Gün } & \\ 09.05 .2013 & 6 \text { Gün } & \\ \text { Kullanilan İzin Toplami: } 187 \text { Gün }\end{array}$

Diğer yandan işe başlama tarihi olan 01.07.2000'den emekliye ayrıldığı tarihe kadar hak edilen izinler hesaplanmış, kullanılan izinler toplam hak edilen izin sürelerinden çıarılarak Tablo 4'te sunulmuştur. 
Tablo 4. Y1llık İzin Alacaklarına İlişkin Hesaplama

\begin{tabular}{|c|c|c|c|c|}
\hline \multicolumn{5}{|c|}{ YILIK İZIN HESAPLAMA } \\
\hline KIDEM & İZNE HAK & 1457 SAYILI & TİS İLE & TOPLAM HAK \\
\hline 1. YIL & 01.07 .2001 & 12 & & 12 \\
\hline 2 YIL & 01.07 .2002 & & 30 & 30 \\
\hline 3. YIL & 01.07 .2003 & & 30 & 30 \\
\hline 4. YIL & 01.07 .2004 & & 30 & 30 \\
\hline 5. YIL & 01.07 .2005 & & 30 & 30 \\
\hline 6. YIL & 01.07 .2006 & & 30 & 30 \\
\hline 7. YIL & 01.07 .2007 & & 30 & 30 \\
\hline 8. YIL & 01.07 .2008 & & 30 & 30 \\
\hline 9. YIL & 01.07 .2009 & & 30 & 30 \\
\hline 10. YIL & 01.07 .2010 & & 30 & 30 \\
\hline 11. YIL & 01.07 .2011 & & 30 & 30 \\
\hline 12. YIL & 01.07 .2012 & 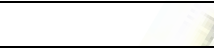 & 30 & 30 \\
\hline \multicolumn{4}{|c|}{ Hak Kazanılan İzin Toplamı } & 342 \\
\hline \multicolumn{4}{|c|}{ Kullanılan İzin } & 187 \\
\hline \multicolumn{4}{|c|}{ Kalan İzin } & 155 \\
\hline \multicolumn{4}{|c|}{ Son Çıplak Ücreti ile çarpımı (TL) } & $45,57 \times 155$ Gün \\
\hline \multicolumn{4}{|c|}{ Toplam Yıllık İzin Tutarı (Brüt) } & $7.063,35$ \\
\hline
\end{tabular}

Kaynak: Yazar tarafından üretilmiştir.

Sonuç olarak davalı ABC Belediyesi kayıtlarının yerinde incelenerek, davacı Ahmet X'in çalışma saatlerini gösterir; nöbet çizelgeleri, puantaj kayıtları, Sosyal yardım alacağına ilişkin ödeme belgeleri, İlave tediye alacağına ilişkin tüm belgeler, hesap özeti, ödemelerin ne şekilde yapıldı̆̆ının belirlenmesi konularında yapılan incelemeler ve tespitler aşağıdaki gibi özetlenebilir.

Davalı ABC Belediyesi, davacı Ahmet X'e ait ekte sunulan ilave tediye bordro ve banka ödeme belgeleri haricinde nöbet çizelgeleri, puantaj kayıtları, Sosyal yardım alacağına ilişkin ödeme belgeleri, diğer ilave tediye alacaklarına ilişkin belgeler ve hesap özetlerini ibraz edememiştir (mevcut değil).

Görevlilerin ifadelerinden ve sunulan ilave tediye ödeme belgelerinden anlaşıldığı üzere ödemelerin, 2006 yılına kadar elden, bu tarihten 2013 yılına kadar Z Bankası T Şubesi aracığıyla, 2013 yılından sonra ise aynı bankanın M şubesinden yapılmıştır.

İlave Tediye Alacak Tutarı: 9.610,28 TL/Brüt

Hafta Tatili Alacak Tutarı : 36.788,56 TL/Brüt

UBGT Alacak Tutarı $\quad$ : 2.702,01 TL/Brüt 
Y1llık İzin Alacak Tutarı : 7.063,35 TL/Brüt

Nihai karar mahkemenin olmak üzere davacının toplamda 56.164,20 TL/Brüt alacağının söz konusu olduğu, ödeme sırasında yasal kesintilerin dikkate alınması gerektiği belirtilerek mahkemenin takdirlerine sunulmuştur.

\section{SONUÇ}

İşçi ve işveren arasındaki iş ilişkisi muhasebe mesleğinin faaliyet konuları arasındadır. İş akdinin imzalanmasıyla birlikte işe giriş bildirgesinin verilmesi, ödenecek ücret ve ekleri gibi ödemelerin yapılması, hatta iş akdinin feshiyle işçiye ibranamenin imzalatılmasına kadar ki süreç muhasebe mensuplarının kontrolünde gerçekleşmektedir. Dolayısıyla mahkemeler işçi alacak davalarında sıklıkla muhasebe bilirkişilerine başvurmakta, bu alanda ihtiyaç olunan özel ve teknik bilgileri meslek mensuplarından sağlamaktadır.

Türkiye'de bilirkişilik uygulamalarında görülen sorunların giderilmesi ve etkin bir yapının tesisi için 6754 sayılı Bilirkişilik Kanunu ile pek çok düzenleme yapılmıştır. Bu düzenlemeler bilirkişilik müessesesini kurumsallaştırmış, belirli standartlarla bilirkişilerin niteliklerini artırmıştır. Ancak bazı sorunlar geçmişten günümüze hala devam etmektedir. Mahkemelerce görevlendirilen bilirkişilere dosyalar halen elden teslim edilip elden teslim alınmakta, mahkeme kalemlerine gidip gelmek oldukça zaman almaktadır. Esasında bu sorun UYAP Bilirkişi Sisteminin etkin bir şekilde kullanılmasıyla çözülebilir. Ancak bunun için mahkeme kalemlerinde çalışan personelin sisteme tam anlamılla adapte olması gerekir. Bir başka sorun ise bilirkişi ücretlerinin verilen emeği karşılamamasıdır. Bu da çoğu meslek mensubunun bilirkişilik konusuna mesafeli durmasına neden olmaktadır.

Sonuç olarak, muhasebe bilirkişiliği konusu ele alınan çalışmada, işçi alacakları ile ilgili örnek bir davada mahkemenin bilirkişiden cevaplandırmasını istediği sorular üzerinde durulmuş, hukuki olgulara fazla girmemeye özen gösterilerek çalışma tamamlanmıştır. İleride yapılacak benzer çalışmalarda mali konuları içeren diğer dava türleri örnek olaylar aracılığıyla incelenebilir, muhasebe bilirkişiliği kapsamında literatür oluşmasına katkı sağlanabilir. 


\section{KAYNAKÇA}

Aksu, Uğur ve Çukacı (2008). Adli Muhasebe ve Adli Muhasebe Mesleğinin Bir Kolu Olarak Bilirkişilik, Yönetim ve Ekonomi Araştırmaları Dergisi, 8 (9), 63-71.

Akyel, N. (2016) Adli Muhasebe Çerçevesinde Hukuk Eğitiminde Muhasebe Derslerinin Önemi, Uluslararası Yönetim İktisat ve İşletme Dergisi (ICAFR'16) Özel Sayısı, 95-108.

ASMMMO, (2017) Bilirkişilik Temel Eğitimi Kaynak Kitabı ve Bilirkişilik Temel Eğitimi Katılımcı El Kitabı, Adalet Bakanlığı Bilirkişilik Daire Başkanlığı Ankara.

Bozkurt, H. (2009). İş Mahkemelerinde Bilirkişilik, Ankara Barosu Dergisi, (4), 117-125.

Brennan, N. M. (2005). Accounting Expertise in Litigation and Dispute Resolution, Journal of Forensic Accounting, VI (2): 13-35.

Çelik, H. ve Bingöl, O. (2016). İş ve Sosyal Güvenlik Hukuku, 14. Baskı, Ekim Basım Yayın Dağıtım.

Erdoğan, E. (2017). Bilirkişilik, (Editör: Talat CANPOLAT), Bilirkişilik Temel Eğitim Kaynak Kitabı ve Bilirkişilik Temel Eğitimi Katılımcı El Kitabl, Adalet Bakanlığı Bilirkişilik Daire Başkanlığı Ankara.

Kisacık, H. (2018). Adli Muhasebe ve 6754 Sayılı Bilirkişilik Kanunu Kapsamında Muhasebe Bilirkişiliği, Elektronic Turkish Studies, 13 (15), 291-303.

Köroğlu, H. (2001). Türk Mahkemelerinde Bilirkişilik ve Bilirkişi Kurumları, Seçkin Yayıncılık, Ankara

Meriç, A., Erkuş, H. ve Kaygusuzoğlu, M. (2016). Bilirkişilik Müiessesesinde Yaşanan Sorunlarla İlgili Muhasebe Meslek Mensupları ve Hâkimlerin Algısı Üzerine Bir Araştırma, Muhasebe ve Finansman Dergisi, (71), 23-48.

Mülayim, B. O. (2018) İşçi Alacaklarına İlişkin Davalarda Net Tutar Yerine Brüt Tutar Üzerinden Karar Verilmesi, İnönü Üniversitesi, Hukuk Fakültesi Dergisi - İnÜHFD, 9 (2), 455-484.

Organ, İ. ve Sevinç, C. (2016). Vergi Yargılamasında Bilirkişilik Kurumu ve Bilirkişilik Kanun Tasarısının Getireceği Yenilikler, Maliye Dergisi, (170), 116-130.

Sanchez, M. H. And Zhang, S. W. (2012). The Role of The Expert Witness in Accounting Fraud Cases, Global Journal of Business Research, 6 (1), 103-111.

Selimoğlu, S. K., Özbirecikli, M., Uzay, Ş., Kurt, G., Alagöz, A. ve Yanık, S. (2014). Muhasebe Denetimi, 4. Baskı, Gazi Kitabevi.

Soydan, B. ve Biyan, Ö. (2016). Bilirkişilik Kurumsallaşıyor mu? Bilirkişilik Kanunu Kapsamında Bir Değerlendirme, Vergi Sorunları Dergisi, (339), 126-145.

Toraman, B. (2017). Bilirkişi İncelemesi (Editör: Talat CANPOLAT), Bilirkişilik Temel Eğitim Kaynak Kitabı ve Bilirkişilik Temel Eğitimi Katılımo El Kitabı, Adalet Bakanlığı Bilirkişilik Daire Başkanlığı Ankara.

Utku, M. ve Kurtcebe, E. (2019). Yeni Bilirkişilik Mevzuatı Çerçevesinde Muhasebe Meslek Mensuplarına Verilen Bilirkişilik Temel Eğitimleri Üzerine Bir Değerlendirme, Alanya Akademik Bakış, 3(3), 261-276.

Ylldız, G. (2013). Genel Muhasebe, Ankara, Detay Yayıncilık.

1475 sayılı İş Kanunu, Kabul Tarihi: 25.08.1971, Yayımlanan Resmi Gazete: 13943.

4857 sayılı İş Kanunu, Kabul Tarihi: 22.05.2003, Yayımlanan Resmi Gazete: 25134.

6772 sayılı Devlet ve Ona Bağlı Müesseselerde Çalışan İşçilere İlave Tediye Yapılması Hakkındaki Kanun, Kabul Tarihi: 04.07.1956, Yayımlanan Resmi Gazete: 9355.

6100 sayılı Hukuk Muhakemeleri Kanunu, Kabul Tarihi: 12.01.2011, Yayımlanan Resmi Gazete: 27836.

Yargitay Kararları, 9. Hukuk Dairesi, E.2017/6387, K.2018/8929, T.17.4.2018.

Yargitay Kararları, 7. Hukuk Dairesi, E.2013/2406, K.2013/6001, T.9.4.2013. 
Yargitay Kararları, Hukuk Genel Kurulu, E.2015/9-3555, K.2018-184.

http://akademikhukuk.org/isci-alacaklari-nelerdir/ Erişim Tarihi: 15.01.2020

tps://www.bilgi.edu.tr/tr/etkinlik/6925/is-hukukunda-hesap-bilirkisiligi-uzmanlik-egitimi6donem/ Erişim Tarihi: 10.02.2020

https:// bilirkisilik.adalet.gov.tr Erişim Tarihi: 18.01.2020

https://www.isvesosyalguvenlik.com/takdiri-indirim-nedir-hangi-iscilik-alacaklarina-uygulanir/ Erişim Tarihi: 09.02.2020

https://www.isveiscidavalari.com/fazla-mesai-alacagi-hakkaniyet-indirimi.html

Erişim Tarihi: 17.02 .2020

https://www.nevzaterdag.com/is-hukukunda-zamanasimi/

https://sozluk.gov.tr/ Erişim Tarihi: 08.01.2020 